\title{
A INTEGRAÇÃO CURRICULAR NA PERCEPÇÃO DOS ESTUDANTES DE TRÊS CÂMPUS DO INSTITUTO FEDERAL DE SANTA CATARINA ${ }^{1}$
}

\author{
Adriano Larentes da Silva*, Saionara Greggio, Sandra A. Antonini Agne \\ ${ }^{*}$ E-mail: adriano.larentes@gmail.com \\ Instituto Federal de Educação, Ciência e Tecnologia de Santa Catarina, Chapecó, Brasil \\ DOI: 10.15628/rbept.2020.7929 \\ Artigo submetido em nov/2018 e aceito em jan/2020
}

\begin{abstract}
RESUMO:
A oferta de cursos técnicos integrados ao Ensino Médio, estimulada a partir do Decreto 5.154/2004, está presente hoje em todo o Brasil. O objetivo deste artigo é mostrar os resultados de uma pesquisa que investigou as percepções de estudantes de cursos integrados em relação ao potencial integrador dos componentes curriculares Oficina de Integração (OI) e Projeto Integrador (PI) nos cursos integrados, ofertados em três câmpus do Instituto Federal de Santa Catarina. Os dados foram coletados por meio de questionário online, que foi respondido por 141 estudantes. A análise dos dados mostra que, nos três câmpus, a maioria dos estudantes percebe o elemento da diferença do $\mathrm{PI}$ e da Ol em relação aos demais componentes curriculares do curso, evidenciado principalmente através da categoria empírica "Processos Metodológicos". Também foi possível identificar, pelas percepções dos estudantes, o potencial integrador desses componentes em cada curso. Para a maioria dos estudantes, a presença das diferentes áreas nas aulas de OI/PI contribui para promover a integração entre os componentes curriculares dos cursos.
\end{abstract}

Palavras-chave: Ensino médio integrado. Integração curricular. Percepções dos estudantes.

\section{STUDENTS' PERCEPTIONS ON CURRICULAR INTEGRATION IN THREE CAMPUSES OF FEDERAL INSTITUTE OF SANTA CATARINA}

\begin{abstract}
:
The offer of technical courses integrated to secondary education, stimulated by the Decree 5.154 /2004, is a reality today all over Brazil. The objective of this article is to show the results of a research that investigated the students' perceptions of integrated courses in relation to the integrative potential of the curricular components Integration Workshop (IW) and Integrator Project (IP) in the integrated courses offered in three campuses of the Federal Institute of Santa Catarina. Data were collected through an online questionnaire, which was answered by 141 students. The analysis shows that, in the three campuses, most students perceive the element of the difference of the IW and IP in relation to the other curricular components of the course, evidenced mainly through the empirical category "Methodological Processes". It was also possible to identify, through the students' perceptions, the integrative potential of these components in each course. For most students, the presence of the different areas in the IW and IP classes contributes to promote integration between the curricular components of the courses.
\end{abstract}

Keywords: Integrated secondary education. Curricular integration. Students' perceptions.

\footnotetext{
${ }^{1}$ Trabalho apresentado no II Seminário Nacional do Ensino Médio Integrado, realizado em Brasília, em agosto de 2018. Pesquisa realizada com apoio financeiro da Pró-Reitoria de Pesquisa, PósGraduação e Inovação do IFSC.
} 


\section{INTRODUÇÃO}

A oferta de cursos técnicos integrados ao Ensino Médio, estimulada a partir do Decreto 5.154/2004, está presente hoje em todo o Brasil. De acordo com esse decreto, o Ensino Médio Integrado (EMI) é voltado à conclusão do nível médio e de uma habilitação profissional técnica em uma mesma instituição de ensino, a partir da construção de um projeto pedagógico único (BRASIL, 2004).

A implementação do currículo integrado na prática, entretanto, continua sendo uma questão bastante desafiadora nos contextos escolares brasileiros que ofertam cursos técnicos integrados ao Ensino Médio. Isso faz com que, muitas vezes, haja uma grande distância entre as intenções presentes nos projetos pedagógicos de cursos integrados e as práticas concretas em sala de aula. De acordo com Silva (2014), entre os inúmeros desafios do currículo integrado estão a realização de um trabalho interdisciplinar a partir de uma perspectiva de totalidade, a superação das hierarquias construídas historicamente entre as áreas do conhecimento e a abertura dos envolvidos para o trabalho coletivo e para novas experiências pedagógicas.

O principal desafio na construção de um currículo integrado, no entanto, tem sido o rompimento da histórica dualidade entre a formação técnica e a formação geral para uma formação humana, baseada no trabalho como princípio educativo e na pesquisa como princípio pedagógico (FRIGOTTO; CIAVATTA; RAMOS, 2005). Em busca dessa superação, contextos educacionais por todo o Brasil, que ofertam cursos técnicos integrados, têm buscado construir um currículo que supere essa dualidade. Dentre esses contextos, destacam-se os Institutos Federais de Educação, Ciência e Tecnologia, hoje espalhados por todo o território nacional e, nos quais havia, em 2018, segundo dados da Plataforma Nilo Peçanha, 236.700 estudantes matriculados em 2.122 cursos técnicos integrados (BRASIL, 2019).

No Instituto Federal de Santa Catarina (IFSC), os debates para a oferta de cursos integrados iniciaram em 2005, culminando na implantação dos primeiros quatro projetos de cursos integrados, a partir de 2006, no Câmpus Florianópolis (ALMEIDA, 2010). A ampliação da oferta de cursos técnicos integrados ocorreu especialmente a partir da instalação de novos câmpus dessa instituição em todas as regiões do estado de Santa Catarina e, atualmente, a grande maioria dos vinte e dois de seus câmpus ofertam pelo menos um curso técnico integrado, totalizando 39 cursos, de acordo com os dados do processo de ingresso do semestre 2018.1 (IFSC, 2017a, IFSC, 2017b, IFSC 2017c).

A ampliação dessa oferta motivou o Grupo de Estudo e Pesquisa e Currículo Integrado (GEPCI), do IFSC, Câmpus Chapecó, a direcionar seu olhar investigativo para a materialização do currículo integrado nessa Instituição. A primeira pesquisa realizada pelo GEPCI, com o objetivo de investigar o currículo integrado nos cursos técnicos do IFSC, foi desenvolvida de agosto de 2014 a julho de 2015, através da análise de treze projetos de cursos integrados. Os resultados dessa investigação mostraram que há diferentes formas de materialização do currículo integrado nessa instituição (POSSAMAI ET AL., 2019). De acordo com os dados dessa pesquisa, apenas seis dos treze projetos analisados explicitavam a preocupação com a integração entre os conhecimentos gerais e técnicos, materializada por meio de um componente curricular específico, intitulado "Oficina de Integração" ou "Projeto Integrador". Dentre os seis projetos, três eram de cursos ofertados pelo IFSC nos câmpus de Chapecó, de São Miguel do Oeste e de Xanxerê, localizados na região 
oeste de Santa Catarina. Em razão disso, os projetos de pesquisa do GEPCI, de 2015 em diante, passaram a focar nos cursos integrados ofertados nesses câmpus. Mais especificamente, o grupo buscou saber como cada curso concebe o currículo integrado e como o mesmo é percebido pelos sujeitos neles envolvidos.

As pesquisas mais recentes, realizadas em 2017, com apoio financeiro da Pró-Reitoria de Pesquisa, Pós-Graduação e Inovação do IFSC, envolveram três cursos integrados: Informática (Chapecó e Xanxerê) e Agroindústria (São Miguel do Oeste) e objetivaram investigar as percepções de professores e estudantes em relação à integração curricular nos cursos técnicos integrados ofertados nesses câmpus. Os dados foram coletados através de questionário e os resultados da análise serão mostrados neste estudo.

Espera-se que este trabalho possa contribuir para uma maior compreensão sobre o ensino médio integrado com vistas ao fortalecimento dessa forma de oferta, tarefa essa fundamental no atual contexto de retrocessos e de ataques às conquistas históricas dos trabalhadores.

\section{OS CAMINHOS DO ENSINO MÉDIO INTEGRADO}

Conforme preveem as Diretrizes Curriculares Nacionais para a Educação Profissional Técnica de Nível Médio (BRASIL, 2012, p. 2-3), os cursos nessa modalidade devem pautar-se, entre outros princípios: a) pela "relação e articulação entre a formação desenvolvida no Ensino Médio e a preparação para o exercício das profissões técnicas, visando à formação integral do estudante"; b) pelo trabalho assumido como princípio educativo e pela pesquisa como princípio pedagógico; c) pela indissociabilidade entre educação e prática social e entre teoria e prática no processo de ensino-aprendizagem; d) pela "interdisciplinaridade assegurada no currículo e na prática pedagógica, visando à superação da fragmentação de conhecimentos e de segmentação da organização curricular". Além disso, esse mesmo documento (BRASIL, 2012, p. 5), ao tratar da organização curricular, enfatiza a necessidade de diálogo entre os diversos campos do trabalho, da ciência, da tecnologia e da cultura como referências fundamentais para a formação e como elementos para compreender e discutir as relações sociais de trabalho e produção. Sobre a organização curricular, as diretrizes propõem:

Organização curricular flexível, por disciplinas ou componentes curriculares, projetos, núcleos temáticos ou outros critérios ou formas de organização, desde que compatíveis com os princípios da interdisciplinaridade, da contextualização e da integração entre teoria e prática, no processo de ensino e aprendizagem. (BRASIL, 2012, p. 7, Grifos nossos).

As Diretrizes Curriculares Nacionais apresentam, portanto, uma perspectiva ampliada para a educação técnica de nível médio, não limitando a formação apenas a uma lógica tecnicista e restrita ao mercado de trabalho. Ao dar ênfase à interdisciplinaridade como princípio, estimula a superação da fragmentação do conhecimento e permite a construção de distintos projetos de curso e estratégias 
que articulem a formação básica e técnica, a preparação para o trabalho e para a vida em sociedade. É nesse escopo que estão também as ofertas do Ensino Médio Integrado em todo o país.

De acordo com Moura e Lima Filho (2017, p. 123) o Ensino Médio Integrado é a concepção mais consistente na perspectiva da formação humana integral na atualidade e permite compreender como unidade a relação das partes no seu todo, a relação entre os diversos conhecimentos, básicos e técnicos, quebrando falsas dicotomias como as que se referem ao geral e ao específico, bem como a integração entre agir e conhecer, teoria e prática.

Para Araújo e Silva (2017, p. 12) a oferta do Ensino Médio Integrado na Rede Federal é uma forma de resistência e de transformação. "É de resistência a um modelo de escola que opera pela lógica da exclusão, pela culpabilização individual do fracasso em relação ao estudante; é de resistência a um modelo de educação abstrato e compartimentalizado, o qual ignora o mundo juvenil".

Como perspectiva de resistência e transformação, o Ensino Médio Integrado encontra-se, desde a sua concepção, em 2004, em meio a diferentes disputas e interesses divergentes, conforme mostram diversos autores (FRIGOTTO; CIAVATTA ; RAMOS, 2005; CIAVATTA; RAMOS, 2012; RIBEIRO; SCHEIBE, 2017). São parte dessas disputas as diferentes proposições e concepções sobre os rumos que os cursos integrados e o Ensino Médio como um todo devem seguir. Tais embates ocorrem tanto em âmbito local, no cotidiano das instituições ofertantes, em âmbito estadual, na definição das políticas e diretrizes institucionais para o ensino médio integrado e também em nível nacional, mais recentemente através de novas ações no âmbito do Ministério da Educação e do Conselho Nacional de Educação. As dimensões dessas disputas e os impactos diretos nos Institutos Federais, no entanto, ainda precisam ser mais bem estudados.

Passados mais de 15 anos da sua implementação, muitas experiências puderam ser acumuladas em todo o Brasil, transformando o ensino médio integrado em referência internacional para a superação dos inúmeros dilemas existentes no contexto do Ensino Médio. Ao mesmo tempo, segundo Araújo e Silva (2017), apesar desses avanços, é preciso aprimorar as experiências levando em conta aspectos como: 1) a necessidade de aperfeiçoar a gestão, a avaliação, a organização curricular, os tempos e os espaços da escola; 2) a importância de uma política consistente e permanente de formação dos profissionais envolvidos; 3) a democratização dos espaços educativos; 4) a construção de condições adequadas de trabalho; e 5) o incentivo a uma maior participação dos estudantes nas definições sobre os caminhos do EMI (IBID, p. 15-17).

O aprimoramento das experiências, no entanto, tal como propõem Araújo e Frigotto (2015, p. 64), "não depende, apenas, de soluções didáticas", mas demandam, principalmente, "soluções ético-políticas". Para esses autores, "a definição clara de finalidades políticas e educacionais emancipadoras e o compromisso com elas próprias é condição para a concretização do projeto de ensino integrado".

Há um duplo movimento que precisa ocorrer para a consolidação do ensino médio integrado na perspectiva da formação humana integral. O primeiro diz respeito às políticas e diretrizes para essa forma de oferta, seja em âmbito institucional, seja em âmbito nacional e internacional. Nesse aspecto, é preciso 
valorizar tudo o que já foi feito até aqui, defendendo o ensino médio integrado como política pública e não cedendo às pressões que podem levar ao seu desmonte e fragmentação. O segundo movimento está relacionado diretamente ao cotidiano da sala de aula, que precisa ainda ser melhor estudado e aprimorado a partir de um trabalho coletivo a ser realizado nos distintos espaços onde as ofertas acontecem. Ao estudar o cotidiano da sala de aula podemos identificar as experiências exitosas ou não, as percepções dos estudantes, professores e todos que atuam no ensino médio integrado e, ao socializar os resultados das pesquisas é possível trocar experiências e avançar no diálogo com outros sujeitos que pesquisam e atuam no contexto do ensino médio integrado.

A superação dos desafios existentes e os caminhos que o ensino médio integrado seguirá depende, portanto, de um movimento mais amplo que leve em conta a totalidade do processo e as suas contradições. Depende também da compreensão e da valorização das experiências em andamento, das lutas e resistências nos distintos locais de oferta e, especialmente, da manutenção das nossas utopias.

\section{O PROCESSO DE INTEGRAÇÃO NA PERCEPÇÃO DOS ESTUDANTES}

Para conhecer as percepções dos sujeitos envolvidos na materialização do currículo integrado no cotidiano escolar da sala de aula, o grupo de pesquisa optou pela coleta de dados através de questionários on-line. O instrumento de pesquisa foi elaborado após debates, leituras e reflexões coletivas, realizadas nas reuniões quinzenais do grupo. Os questionários foram aplicados nos meses de março e abril de 2017 pelos membros do grupo de estudo, atuantes em cada um dos câmpus pesquisados. Nos três câmpus, os estudantes, acompanhados por um professor, responderam ao questionário on-line no laboratório de informática, em um horário cedido pelo curso e previamente agendado para esse fim. Já os docentes responderam ao questionário a partir de convite enviado através do e-mail institucional.

Por se tratar de uma pesquisa extensa e que requer um estudo profundo dos dados coletados, o GEPCl optou por analisar primeiramente os questionários respondidos pelos estudantes. Os questionários respondidos pelos docentes serão objeto de análise em outro estudo. No presente trabalho apresentaremos os resultados da análise dos dados do questionário respondido pelos estudantes.

Embora o questionário, composto por perguntas de múltipla escolha, com a possibilidade de o participante justificar sua resposta, fosse igual para todos os cursos pesquisados, o mesmo foi aplicado em links separadamente para posterior comparação das percepções em cada um dos câmpus. Responderam ao questionário 30 estudantes do câmpus Chapecó, 31 de Xanxerê e 83 do câmpus de São Miguel do Oeste.

Como a aplicação foi feita através da ferramenta Google Docs, imediatamente após a aplicação já foi possível visualizar os gráficos das respostas das perguntas de múltipla escolha. Entretanto, como em todas as questões havia também a possibilidade de justificar a resposta, a maioria dos participantes apresentou suas justificativas, o que, por sua vez, veio a contribuir ainda mais para 
o alcance do objetivo pretendido com a pesquisa. Para tanto, porém, foi necessário primeiramente sistematizar e categorizar o conteúdo das justificativas, para posteriormente analisá-lo juntamente com os dados dos gráficos.

A sistematização e a categorização foram feitas coletivamente pelos membros do grupo de pesquisa e aconteceu nas seguintes etapas, baseadas em Minayo (2009): 1) Subcategorias de análise: em cada pergunta, o grupo elencou frases temáticas que expressassem a ideia geral transmitida pelas respostas; 2) Categorias de análise empírica: esse processo buscou agrupar as subcategorias de análise em frases temáticas mais amplas; 3) Categorias filosóficas: as categorias de análise empírica foram expressas por meio de um conceito mais abrangente.

Anteriormente à apresentação dos resultados, no entanto, faz-se necessário esclarecer que, embora nos três câmpus, os cursos pesquisados sejam técnicos integrados, em cada um deles a integração se efetiva de diferentes formas e por meio de distintas estratégias. É importante salientar também que o foco da pesquisa realizada foram as Oficinas de Integração (Ols) e os Projetos Integradores (PIs), pois ambos apresentam-se nos projetos pedagógicos dos respectivos cursos como componentes curriculares estratégicos para avançar na interdisciplinaridade e na integração curricular.

No câmpus do IFSC de Xanxerê, o componente curricular "Projeto Integrador" (PI) é ofertado no penúltimo semestre do curso de Informática. No câmpus de São Miguel do Oeste, a matriz curricular também apresenta o componente curricular "Projeto Integrador", porém sendo ofertado nos dois últimos semestres do curso de Agroindústria. Já no curso Técnico em Informática do câmpus Chapecó, a nomenclatura do componente curricular é "Oficina de Integração" (OI) e é ofertado nos quatro semestres ímpares do curso.

Outra diferença nos cursos pesquisados é a forma como o componente curricular em análise é trabalhado. No curso técnico em Informática do câmpus Chapecó, participam das "Oficinas de Integração" (Ols) pelo menos um educador de cada área do conhecimento, de forma rotativa. No final de cada semestre, os professores indicam a oficina da qual querem fazer parte no semestre seguinte, resultando, geralmente, em equipes de 4 a 6 professores para cada uma das Ols. A equipe, então, reúne-se para o planejamento do trabalho que será desenvolvido no componente curricular ao longo do semestre. O grupo não só planeja as aulas coletivamente, como também vai todo para a sala de aula para implementar o trabalho planejado. Após as etapas de problematização e instrumentalização, que ocupam em torno de cinquenta por cento da carga horária semestral do componente curricular, os estudantes passam a focar em um tema de pesquisa. Nessa etapa, os professores atuam como orientadores dos trabalhos de pesquisa. Uma síntese sobre as experiências e o trabalho realizado, desde 2011, nas Oficinas de Integração foi publicado por Silva (2019).

No câmpus de São Miguel do Oeste, o componente "Projeto Integrador" é conduzido por dois professores. Um de Língua Portuguesa, que orienta os estudantes na escrita do projeto e outro, o responsável pela unidade curricular, que trabalha a metodologia científica. No "Projeto Integrador I", os estudantes definem o tema de pesquisa e têm noções de projeto de pesquisa, já no "Projeto Integrador II", desenvolvem o trabalho de pesquisa. Em ambos os semestres, os estudantes contam também com a orientação de outros professores do curso, de acordo com a temática de seu projeto de pesquisa. Esses professores, no entanto, não participam 
do processo de planejamento das aulas de "Projeto Integrador", atuam especificamente como orientadores das pesquisas. Já no câmpus de Xanxerê, o componente PI é conduzido apenas por um professor e, assim como no câmpus de São Miguel do Oeste, os demais professores do curso atuam apenas como orientadores das pesquisas dos estudantes.

Esse esclarecimento é importante, pois mostra que há uma diversidade de propostas na implementação dos currículos dos cursos técnicos integrados. Cada câmpus, do seu modo, procura promover a integração entre as áreas da formação geral e da formação técnica. Entretanto, embora o objetivo final seja o mesmo nos três câmpus pesquisados, ou seja, que os estudantes desenvolvam um trabalho de pesquisa, através do qual possam integrar tanto os conhecimentos da formação geral quanto os da formação técnica, a percepção deles, dos estudantes, é diferente de um câmpus para outro, conforme mostram os resultados a seguir.

Em relação à primeira pergunta, que objetivou saber se os participantes consideravam o componente curricular $\mathrm{Pl} / \mathrm{Ol}$ igual ou diferente dos demais componentes curriculares do curso, os resultados obtidos foram:

Tabela 1 - Percepção dos estudantes sobre OI/PI (1)

\begin{tabular}{|c|c|c|c|}
\hline & Chapecó & São Miguel & Xanxerê \\
\hline Igual & $6,7 \%$ & $1,2 \%$ & $3,2 \%$ \\
\hline Diferente & $63 \%$ & $53 \%$ & $67,7 \%$ \\
\hline $\begin{array}{c}\text { Igual em alguns } \\
\text { aspectos e diferente } \\
\text { em outros }\end{array}$ & $30 \%$ & $45,8 \%$ & $29 \%$ \\
\hline
\end{tabular}

Fonte: Elaboração própria.

Conforme pode-se perceber nos resultados apresentados na Tabela 1, para a maioria dos estudantes, nos três câmpus pesquisados, o componente curricular $\mathrm{PI} / \mathrm{OI}$ difere-se dos demais componentes do curso. A partir da análise das justificativas das respostas, foram identificadas duas categorias empíricas, que caracterizam os elementos da diferença desse componente curricular em relação ao demais: Processos Metodológicos e Organização Curricular.

Quanto a Processos Metodológicos, os estudantes argumentam que as unidades integradoras de $\mathrm{PI}$ e Ol estimulam a criatividade, permitindo a liberdade de escolha das temáticas abordadas, incentivando à pesquisa, através da utilização de diversas estratégias metodológicas, que priorizam atividades em grupo, trabalhos 
práticos, aulas de campo e visitas de estudo. Segundo o estudante $\mathrm{A} 1^{2}$, "a proposta da disciplina é diferente das outras, ela trabalha a criatividade, uma experiência nova com a qual eu nunca tinha tido contato até conhecer o IFSC". Os estudantes destacam, também, que as unidades integradoras aproximam o estudante da comunidade, abordando temas do cotidiano, buscando soluções para problemas da comunidade, transformando a escola num lugar para debates, discussões e muita aprendizagem.

$\mathrm{Na}$ categoria Organização Curricular destacou-se como elemento da diferença a forma como os conteúdos são trabalhados, através de atividades interativas e dinâmicas entre as unidades curriculares, professores e módulos, priorizando o desenvolvimento de projetos, com planejamento específico, potencializando a autonomia dos sujeitos no processo, através da escolha das temáticas estudadas. Para o estudante A2, "essa disciplina dá oportunidade de colocar em prática o que você aprendeu, vai além da sala de aula, abre sua visão, mostra uma maneira diferente de pesquisar e estudar".

Destaca-se também que a integração está para além das unidades curriculares, perpassa todos os segmentos envolvidos e o meio onde vivem, possibilitando uma abordagem da realidade como totalidade, criando um espaço favorável para que todos possam ampliar sua leitura de mundo, refletir sobre e transformá-lo no que julgarem necessário. Conforme defende Kuenzer (2002, p. 43), o ensino integrado tem por objetivo "disponibilizar aos jovens que vivem do trabalho a nova síntese entre o geral e o particular, entre o lógico e o histórico, entre a teoria e a prática, entre o conhecimento, o trabalho e a cultura".

Além de buscar saber se os participantes consideravam o componente curricular $\mathrm{Pl} / \mathrm{Ol}$ igual ou diferente dos demais componentes curriculares do curso, também perguntamos se eles achavam o referido componente curricular mais fácil ou mais difícil que os demais. Os resultados quantitativos dessa questão mostraram que para a maioria dos participantes dos câmpus de Chapecó $(76,7 \%)$ e de Xanxerê $(61,3 \%)$ a/o Ol/PI não é nem mais fácil, nem mais difícil que os demais componentes curriculares. Já no câmpus de São Miguel do Oeste, para a maioria dos estudantes participantes da pesquisa (62,7\%), o componente curricular em questão é "mais difícil" que os demais.

Os participantes do câmpus Chapecó e de Xanxerê, em sua maioria, classificam a/o Ol/PI como "Nem mais fácil, nem mais difícil que as outras", justificando que esse componente curricular exige deles o mesmo grau de estudo e esforço que os demais componentes. Entretanto, apontam que a dedicação à/ao $\mathrm{OI} / \mathrm{PI}$ é empregada para fins diferentes das demais disciplinas, considerando que na/no OI/PI é necessário desenvolver um trabalho final, que requer conhecimento e cooperação de todos para trabalhar em grupo.

\footnotetext{
${ }^{2}$ Para garantir a autoria das justificativas dos participantes desse estudo, foi adotada a identificação A (de aluno), seguida de um número cardinal, resultando nos códigos A1, A2, A3 e, assim sucessivamente.
} 
Já no caso do Projeto Integrador de São Miguel do Oeste, os dados mostram que para a maioria dos estudantes, esse componente é "Mais difícil", predominando, nas justificativas, argumentos de que $\mathrm{O} P \mathrm{Pl}$ exige muita criatividade e $\mathrm{O}$ desenvolvimento de algo "novo". A análise das justificativas também revelou a preocupação dos estudantes em relação à dificuldade de criar um projeto inovador, pois, segundo eles, não possuíam os conhecimentos necessários para tal exigência.

Independentemente do resultado quantitativo obtido em cada um dos câmpus nessa questão, o principal achado está na análise das justificativas dadas pelos estudantes para suas respostas. Novamente, independentemente da resposta dada, "Nem mais fácil nem mais difícil", "Mais difícil" ou "Mais fácil", o fato é que as justificativas dadas resultaram em uma única categoria de análise empírica: Processos Metodológicos. Em uma análise mais aprofundada dessa categoria, constatou-se que os estudantes referiam-se, direta ou indiretamente, a dois tipos de processos metodológicos: objetivos e subjetivos.

A categoria Processos Metodológicos Objetivos emergiu de justificativas dadas pelos participantes dos câmpus de Chapecó e de Xanxerê, que apontaram que o componente $\mathrm{PI} / \mathrm{OI}$, embora "nem mais fácil nem mais difícil", diferencia-se dos demais por suas atividades, especialmente por envolver a produção de um projeto e o desenvolvimento de um trabalho de pesquisa. Já a categoria Processos Metodológicos Subjetivos emergiu das justificativas dadas pelos participantes do câmpus de São Miguel do Oeste, que apontaram que o componente PI, é "mais difícil" porque exige deles mais dedicação e esforço, devido, principalmente, à obrigatoriedade de produção de um projeto e o desenvolvimento de um trabalho de pesquisa.

Em relação à terceira pergunta, que objetivou saber se os participantes percebiam a integração entre os componentes curriculares do curso no componente curricular $\mathrm{PI} / \mathrm{Ol}$, o resultado obtido nos três câmpus foi predominantemente "sim". No entanto, uma parte dos estudantes respondeu que "não" ou "em partes", como pode-se observar na Tabela 2 a seguir:

Tabela 2 - Percepção dos estudantes sobre OI/PI (2)

\begin{tabular}{|c|c|c|c|}
\hline & Chapecó & $\begin{array}{c}\text { São } \\
\text { Miguel }\end{array}$ & Xanxerê \\
\hline Sim & $70 \%$ & $62,7 \%$ & $51,6 \%$ \\
\hline Não & - & $6 \%$ & $9,7 \%$ \\
\hline $\begin{array}{c}\text { Em } \\
\text { partes }\end{array}$ & $30 \%$ & $31,3 \%$ & $38,7 \%$ \\
\hline
\end{tabular}

Fonte: Elaboração própria. 
A análise das justificativas de quem respondeu "sim" identificou como categoria de análise empírica a Organização Curricular, que apresentou-se tanto para as respostas das Ols de Chapecó, como para as respostas dos Pls de SMO e Xanxerê. Nesta categoria, destacaram-se como subcategorias: Interdisciplinaridade, Participação de mais de um professor, Pedagogia de projetos, Eixos temáticos, Temas, Conteúdos e sua relação com a sociedade e o cotidiano. Outra categoria de análise empírica que apareceu em um dos câmpus foi Processos Metodológicos, cujas subcategorias de análise foram Metodologia e Interação.

Ao justificar que a integração acontece nas Ols/PIs, o estudante A3, por exemplo, afirma que: "tem-se a possibilidade de toda a semana interagir, pensar e resolver problemas em grupo". Ou seja, esses componentes curriculares proporcionam aos estudantes a construção de uma identidade coletiva e de grupo. Além disso, nas/nos Ols/Pls, as reflexões, os temas, as abordagens ocorrem buscando ampliar as relações entre as várias áreas do conhecimento, conforme mostra a justificativa do estudante A4: "há a integração, pois são mostradas as perspectivas de várias áreas da ciência em uma única aula". Outros elementos presentes nas justificativas são "a liberdade de falar", "abordagem de vários assuntos", "a integração entre as unidades curriculares técnicas e propedêuticas", etc.

A análise das justificativas das respostas "não" e "em partes" mostra que a integração curricular depende de muitos fatores, principalmente em relação ao tema abordado, por vezes desconectado do contexto estudado e da participação das unidades curriculares. Desta forma, pode-se considerar que em algumas Oficinas de Integração ocorre uma integração parcial, conforme mostra a justificativa do estudante A5: "Algumas oficinas foram melhores que outras, há assuntos que não se relacionam com as unidades e alguns professores não conseguem estabelecer relação". Outro elemento apontado nas justificativas é a dificuldade de integração nos módulos finais, possivelmente pela concentração de componentes curriculares da área técnica ou pela falta de articulação entre esses componentes.

Em relação à quarta pergunta, que objetivou saber se os participantes consideravam importante ter mais de um professor na sala de aula, no componente curricular PI/OI, os resultados obtidos para a resposta "Sim" foram: $100 \%$ no câmpus Chapecó, 90,3\% no de Xanxerê e 65,1\% no de São Miguel do Oeste. Para entendermos o significado desses números é necessário considerarmos como cada projeto de curso concebe o componente curricular em análise.

Conforme mencionado anteriormente, no câmpus Chapecó a Ol é conduzida por um grupo de professores, que além de planejar as aulas coletivamente, também vai todo para a sala de aula na implementação do trabalho planejado. Isso justifica o fato de todos os estudantes terem respondido que é importante ter mais de um professor na aula da OI. Ou seja, a unanimidade da resposta "Sim" resulta da experiência de ter vários professores atuando conjuntamente. 
Pode-se perceber, também, na Tabela 2, o alto índice de participantes dos cursos integrados do câmpus de Xanxerê que responderam "Sim". Contudo, como nesse câmpus o componente "Projeto Integrador" é conduzido apenas por um professor, esse resultado pode significar a necessidade que os estudantes sentem de ter as várias áreas do curso envolvidas na condução do PI para, de fato, haver a integração curricular. Isso foi possível verificar nas justificativas dos estudantes, desse câmpus, para o "Sim". O estudante A6, por exemplo, argumenta: "Sim, pois assim todos podemos adquirir mais e mais conhecimentos, pois são várias áreas diferentes trabalhando ao mesmo tempo". Já na percepção de A7: "Para que assim possamos juntar todas as disciplinas e trabalhar em equipe, com várias áreas do conhecimento envolvidas".

Ao analisarmos as justificativas dadas pelos estudantes para a resposta "Sim", nos três câmpus, identificamos as seguintes categorias de análise empírica: Integração e Processos Metodológicos. Na categoria Integração, as subcategorias mais recorrentes foram Interação, Cooperação, Conhecimento e Interdisciplinaridade.

A maioria das justificativas apresentadas pelos estudantes que responderam "Sim" indica que a condução da/do Ol/PI por mais de um professor em sala de aula é importante porque, por serem de diferentes disciplinas e áreas, os professores têm diferentes pontos de vista, de opinião sobre os temas, o que por sua vez, promove o diálogo entre as áreas em sala de aula e contribui para melhor compreensão do conteúdo. O estudante A8, por exemplo, argumenta: "É muito mais fácil trabalhar com as temáticas das Ols quando se tem vários professores, pois eles podem nos mostrar diferentes pontos dessas temáticas, além de ajudar muito na integração das várias disciplinas", já na percepção do estudante A9: "A colaboração entre as disciplinas traz riqueza e diversidade para o projeto".

Em relação à categoria Processos Metodológicos, as subcategorias que emergiram da análise das justificativas foram Metodologia, Orientação e Experiência Discente. Foi recorrente, nas respostas dos estudantes que justificaram por que é importante a Oficina de Integração/o Projeto Integrador ser desenvolvida/o por mais de um professor em sala, o fato de eles poderem contar com o auxílio de um grupo de professores, tanto durante as aulas em si, através dos diferentes pontos de vista, quanto durante a realização do projeto e trabalho de pesquisa, etapas subsequentes às aulas ministradas pelos professores e que requerem contínua orientação por parte dos professores, tanto dentro quanto fora da sala de aula. Isso tudo, na percepção dos estudantes, torna a/o OI/PI um componente curricular diferente dos outros, contribuindo, principalmente, para uma experiência discente diferenciada em relação aos demais componentes curriculares do curso, uma vez que os desafia e os coloca em contato direto com as diferentes áreas do conhecimento, através do desenvolvimento de pesquisa. 
Em relação a essa pergunta, nos chamou a atenção que 35\% dos estudantes do câmpus de São Miguel do Oeste acreditam que apenas um professor nas aulas de PI é o suficiente. Esse resultado pode ser decorrente do fato de que, nesse câmpus, as aulas de PI são ministradas por um professor em sala. Contudo, outros professores do curso auxiliam os estudantes como orientadores no desenvolvimento do projeto de pesquisa e um docente de Língua Portuguesa que, nas últimas aulas da disciplina, dá suporte à escrita do projeto. Esse auxílio, possível de ser obtido junto a professores que não atuam no Projeto Integrador, pode ser uma das razões de os estudantes não sentirem a necessidade de mais de um professor no componente PI no curso pesquisado nesse câmpus.

A análise das justificativas para a resposta "Não", dadas pelos estudantes, sugere que o foco da questão para estes estudantes não está na integração em si, mas na possibilidade de obter a assessoria necessária para o sucesso no desenvolvimento do produto final do seu projeto, o que podemos observar nas seguintes justificativas para as respostas: "Não, porque são os estudantes que devem fazer o PI e não seus professores" (A10); "Um professor é suficiente para esclarecer nossas dúvidas mais básicas e se necessário podemos pesquisar mais a fundo ou nós mesmos irmos atrás de outros professores, pois eles sempre estão disponíveis, basta o estudante ir atrás" (A11); "Um professor que consiga tirar dúvidas quanto à formatação do projeto já é suficiente" (A12).

Em relação à quinta pergunta, que objetivou saber para que o componente curricular PI/OI prepara os estudantes, os resultados obtidos foram:

Tabela 3 - Percepção dos estudantes sobre OI/PI (3)

\begin{tabular}{|c|c|c|c|}
\hline & Chapecó & $\begin{array}{c}\text { São } \\
\text { Miguel }\end{array}$ & Xanxerê \\
\hline $\begin{array}{c}\text { Articular conhecimentos das } \\
\text { diferentes áreas }\end{array}$ & $63,3 \%$ & $47,6 \%$ & $25,8 \%$ \\
\hline $\begin{array}{c}\text { O exercício crítico da } \\
\text { cidadania }\end{array}$ & $26,7 \%$ & $3,7 \%$ & $3,2 \%$ \\
\hline O empreendedorismo & $3,3 \%$ & $4 \%$ & $41,9 \%$ \\
\hline O mercado de trabalho & $0 \%$ & $17,1 \%$ & $12,9 \%$ \\
\hline
\end{tabular}

Fonte: Elaboração própria. 
Dos resultados apresentados na Tabela 3, três chamam a atenção. O primeiro é o fato de em dois dos câmpus pesquisados os estudantes terem apontado a "Articulação entre os conhecimentos das diferentes áreas" como objetivo da Ol/do $\mathrm{PI}$. O segundo dado que chama atenção é o fato de que para a maioria dos estudantes do câmpus de Xanxerê, o PI prepara principalmente para o "Empreendedorismo". O terceiro dado relevante de se analisar é o fato de no câmpus Chapecó não ter havido menção à contribuição da OI na preparação para o "Mercado de Trabalho".

Em relação à "Articulação entre os conhecimentos das diferentes áreas", os dados quantitativos evidenciam que nem todos os estudantes têm clareza do principal objetivo do $\mathrm{Pl} / \mathrm{da} \mathrm{Ol}$ no curso que fazem, que é de ser o componente articulador dos conhecimentos das diferentes áreas, ou seja, de ser o componente que deveria potencializar a interdisciplinaridade no curso que, conforme já mencionado, é um dos princípios norteadores da Educação Profissional Técnica de Nível Médio. Uma possível razão para isso é que tal componente não esteja, na prática, promovendo a articulação, apesar de o curso ser integrado.

A percepção de que 0 PI prepara principalmente para 0 "Empreendedorismo", resultado obtido no câmpus Xanxerê, e de que a OI não prepara para o "Mercado de trabalho", no câmpus Chapecó, pode estar relacionada ao fato de os cursos ofertados no câmpus Xanxerê estimularem os estudantes a desenvolverem características de um comportamento empreendedor com ênfase na área técnica, com foco específico na inovação. Já, no curso técnico em Informática do câmpus Chapecó, a ausência da percepção de uma formação para o "mercado de trabalho", possivelmente deve-se ao fato de os estudantes estarem no primeiro semestre do curso e, também, de esse não ter sido o objetivo das aulas de "Oficina de Integração", que no primeiro semestre tem como eixo temático "Ciência, Cultura e Sociedade".

\section{CONSIDERAÇÕES FINAIS}

Nesta pesquisa investigamos as percepções dos estudantes dos cursos integrados do Instituto Federal de Santa Catarina, nos câmpus de Chapecó, de São Miguel do Oeste e de Xanxerê, em relação ao potencial integrador dos componentes curriculares Oficina de Integração e Projeto Integrador nos cursos integrados de Informática e Agroindústria, ofertados nesses câmpus.

Os dados analisados mostraram que, nos três câmpus, a maioria dos estudantes percebe o elemento da diferença do $\mathrm{PI}$ ou da OI em relação aos demais componentes curriculares do curso, evidenciado principalmente através da categoria empírica "Processos Metodológicos".

Também foi possível identificar, pelas percepções dos estudantes, o potencial integrador desses componentes em cada curso. Conforme mostrado, para a maioria dos estudantes, a presença das diferentes áreas na aula de OI/PI contribui para promover a integração entre os componentes curriculares do curso, o 
que, por sua vez, é importante para a formação humana integral, que é um dos objetivos da oferta de cursos técnicos integrados ao ensino médio.

Deve-se salientar que o fato de terem sido estudados as Oficinas de Integração e os Projetos Integradores não significa que os processos de integração curricular nos três câmpus analisados se restrinjam unicamente a esses dois componentes curriculares. Como pesquisadores e partícipes desse processo, sabemos que existem outras estratégias interdisciplinares que tentam avançar para uma perspectiva de totalidade e de rompimento com a dualidade estrutural mencionada no início desse trabalho.

Ao realizar a pesquisa nos três câmpus do IFSC, confirmamos o quanto a oferta do ensino médio integrado e a materialização da integração curricular são processos desafiadores para todos os envolvidos. Ao mesmo tempo, confirmamos que há diversas experiências que buscam avançar e aprimorar essa forma de oferta, mesmo que inexistam, como no caso do IFSC, diretrizes institucionais claras e um debate mais profundo sobre a perspectiva de ensino médio a ser adotada nos diferentes câmpus.

Acreditamos que esse movimento de tentativas e de novas experimentações precisa ser fortalecido e que, por ainda estarmos vivendo um movimento de travessia, iniciado em 2004 (FRIGOTTO, CIAVATTA e RAMOS, 2005), cabe às gestões dos Institutos Federais e ao Conselho Nacional das Instituições da Rede Federal de Educação Profissional, Científica e Tecnológica (CONIF) contribuir com esse processo, estimulando as equipes a continuar com o seu trabalho e resistindo às tentativas recentes de desmonte do ensino médio integrado e da própria rede federal como um todo.

Apesar dos inúmeros desafios existentes, é na rede federal que o ensino médio integrado pode consolidar-se como uma perspectiva contra-hegemônica de ensino médio, permitindo aos filhos dos trabalhadores uma educação plena, integral, omnilateral e emancipadora.

\section{REFERÊNCIAS}

ALMEIDA, Alcides. Da Escola de Aprendizes de Artífices ao Instituto Federal de Santa Catarina. Florianópolis: IFSC, 2010.

ARAÚJO, R.; FRIGOTTO, G. Práticas Pedagógicas e ensino integrado. Revista Educação em Questão. Natal, IFRN, v. 52, n. 38, p. 61-80, maio/ago. 2015. Disponível em: https://periodicos.ufrn.br/educacaoemquestao/article/viewFile/7956/5723\%3E. Acesso em abril de 2018.

ARAÚJO, A.; SILVA, C. Ensino médio integrado: uma formação humana, para uma sociedade mais humana. In: ARAÚJO, A.; SILVA, C. (Orgs.). Ensino Médio Integrado no Brasil: fundamentos, práticas e desafios. Brasília: IFB, 2017. Disponível

em:

http://www.anped.org.br/sites/default/files/images/livro completo ensino medio inte grado - 1310 2017.pdf. Acesso em abril de 2018. 
BRASIL. Decreto no. 5.154/2004. Brasília: Presidência da República/Casa Civil. Disponível em: $\quad$ http://www.planalto.gov.br/ccivil 03/ ato20042006/2004/decreto/d5154.htm. Acesso em: nov. 2017.

BRASIL. Diretrizes Curriculares Nacionais para a Educação Profissional Técnica de Nível Médio - RESOLUÇÃO № 6, DE 20 DE SETEMBRO DE 2012. Brasília: MEC/CNE/CEB, 2012. Disponível em: http://portal.mec.gov.br/index.php?option=com docman\&view=download\&alias=116 63-rceb006-12-pdf\&category slug=setembro-2012-pdf\&ltemid=30192. Acesso em abril de 2018.

Plataforma Nilo Peçanha - Cursos, Matrículas, Ingressantes, Concluintes, Vagas e Inscritos por Tipo de Curso e Tipo de Oferta. Disponível em: http://plataformanilopecanha.mec.gov.br/2019.html. Acesso em dezembro de 2019.

CIAVATTA, M.; RAMOS, M. A "era das diretrizes": a disputa pelo projeto de educação dos mais pobres. Revista Brasileira de Educação, Rio de Janeiro, v. 17 n. 492 jan.-abr. $2012 . \quad$ Disponível em: http://www.scielo.br/pdf/rbedu/v17n49/a01v17n49.pdf. Acesso em maio de 2014.

FRIGOTTO, G.; CIAVATTA, M.; RAMOS, M. A gênese do Decreto n. 5154/2004: um debate no contexto controverso da democracia restrita. In: FRIGOTTO, G.; CIAVATTA, M.; RAMOS, M. (Orgs.). Ensino Médio Integrado: concepções e contradições. São Paulo: Cortez, 2005.

IFSC. Edital 07 - Cursos Técnicos Integrados, Concomitantes e Subsequentes - Ingresso por Sorteio Público - 1o Semestre/2018. Florianópolis: IFSC, 2017a. Disponível:http://www.ifsc.edu.br/documents/177207/674502/EDITAL $0720181 \mathrm{~T}$ ECNICO SORTEIO.pdf/4d8eaefa-443c-1f9c-6f49-008f5408648c. Acesso em abril de 2018.

Edital 02 - Cursos Técnicos Integrados - Ingresso por Exame de Classificação - 1ำ Semestre/2018. Florianópolis: IFSC, 2017b. Disponível:http://www.ifsc.edu.br/documents/177207/674502/EDITAL 0220181 T ECNICO PROVA.pdf/66b185f0-1713-98b3-6441-a368f5ba7658. Acesso em abril de 2018.

Edital 08 - Cursos Técnicos - Câmpus Itajaí - Ingresso por Sorteio Público - 1o Semestre/2018. Florianópolis: IFSC, 2017c. Disponível em: http://www.ifsc.edu.br/documents/177207/674502/EDITAL 0820181 TECNICO SORTEIO ITAJAI.pdf/03d82add-1a7e-b58e-05c3-3b6d5c26a16d. Acesso em abril de 2018.

KUENZER, A. Z. (Org.). Ensino médio: construindo uma proposta para os que vivem do trabalho. 3 ed. São Paulo: Cortez, 2002.

MINAYO, M. (Org.). Pesquisa social: teoria, método e criatividade. Petrópolis: Vozes, 2009.

MOURA, D.; LIMA FILHO, D. A reforma do ensino médio: regressão de direitos sociais. Revista Retratos da Escola, Brasília, v. 11, n. 20, p. 109-129, jan./jun. 2017. Disponível em: <http//www.esforce.org.br>. Acesso em abril de 2018.

POSSAMAI, L.F.L; CARVALHO, M.G.M; GREGGIO, S.; AGNE, S.A.A.; BENINCÁ, E.M. In: SOUZA, F.C.S.; NUNES, A.O. (Orgs.). Temas em Educação Profissional 
e Tecnológica. Campos dos Goytacazes: Essentia Editora IFFluminense, 2019. Disponível em: http://essentiaeditora.iff.edu.br/index.php/livros/article/view/14199/11500. Acesso em dezembro de 2019.

RIBEIRO, M.; SCHEIBE, L. Reforma do ensino médio: pragmatismo e lógica mercantil. Revista Retratos da Escola, Brasília, v. 11, n. 20, p. 19-31, jan./jun. 2017. Disponível em: <http//www.esforce.org.br>. Acesso em abril de 2018.

SILVA, A. L. Currículo Integrado. Florianópolis: Publicações do IFSC, 2014.

SILVA, A.L. (Org.). Oficinas de Integração: vivências de sala de aula no Ensino Médio Integrado. Curitiba: CRV, 2019. 